\title{
The Academic Surgeon
}

\section{Editorial}

G. A. Androulakis

It is a great honor and privilege to have this opportunity to express some of my thoughts regarding the qualitative - if I may call them so - characteristics of the personality of the academic surgeon.

Throughout my long academic career, I have often found myself before the crucial question: what are the qualitative characteristics, the inherent otherwise classed as talent and / or acquired, namely education and skills, that compose the profile of the successful academic surgeon in a position of leadership.

First, however, allow me to attempt to define the concept of the academic surgeon especially since in the anglosaxon bibliography the debate persists as to whether one same person can simultaneously distinguish themselves both as a clinical surgeon and as a theoretical academic teacher.

Many, however, consider this very question an oxymoron or as an antinomy at least in terms of interpreting the term academic, as excessively or exclusively concerned with intellectual matters and lacking experience of practical affairs.

This confusion unfortunately is neither uncommon nor rare when Hellenic terms are transferred to foreign bibliography and then repatriated with a different meaning.

In this case, the very term "academic" refers to the highest educative master, namely the university teacher. Notably, the term itself has its roots in Plato's Academy which was the famous philosophical educative institution founded by the philosopher himself.

Consequently, it transpires that the term "academic" relates to the context of the university teacher and not to that of the theoretical surgeon.

In other words, the profile of the academic surgeon personifies the meaning of surgery as a science and

G. A. Androulakis is Professor of Surgery in Medical School of National and KapodistrianUniversity of Athens

This article initially formed part of lecture given at the opening ceremony of the New European Surgical Academy Congress in May 2009, Athens Greece
Art and clearly explains the label of the surgeon as surgical scientist, as the anglosaxons choose to call the surgeon [1].

It is already clear - I trust - that the academic surgeon maintains a remarkable balance between art and science.

It is precisely the surgery that harmonically combines theory with clinical practice and skills and broad theoretical knowledge. It is the surgeon who is so beautifully painted by the words of Williams Longmire:

"Developing and maintaining the technical skills that will identify an individual as a well trained surgeon and at the same time qualify him or her as a scientist".

These principles which prescribe the academic surgeon remain unaltered through time $[2,3]$. Thus the personality of the academic surgeon is a synthesis and consists of four [4] distinct unities:

a) The Clinical Surgeon b) The Researcher c) The Teacher d) The Administrator and finally e) The Communicator. Allow me please to address them one by one.

\section{The Clinical Surgeon}

I have always believed and continue to do so that first and foremost the academic surgeon must be an excellent and talented surgeon without of course overlooking the fact that history has recorded less talented surgeons who have indeed left behind their distinguished mark as university teachers.

I do believe, however, that the surgeon must continue to be assessed in the operating theater, the source of his prestige or not, wherein he is established as a surgical personality or rejected, where he inspires or fails to inspire, commands the admiration and respect of his colleagues or not, becomes their mentor or disappoints them [1].

In addition, the distinguished academic surgeon does indeed establish the institution in which he works as a medical center of reference, contributing to the advancement and innovation of surgery, providing a hotbed for new surgical talents.

At this point, I must emphasize that when evalu- 
ating and electing new academic members, the parameter of what is considered as a "distinguished surgeon" is not assessed according to the extent of its meaning. Many from the body of electors base their selection mainly on other norms such as, for example, number of papers, citations, impact factors. I believe that this mentality (mode/practice) of judgment must come to an end. This, in my opinion, would be the best way for the teaching hospitals to return to the brilliance as well as the might of the past. It is most unfortunate that in recent years academic surgery finds itself in serious crisis globally.

A recent study in the U.K. (B.M.J: Careers, January 2009) proves that the number of lectures has reduced to half compared to that of 2000.

I do not intend, of course, to proceed with a complete in depth analysis of this phenomenon; however, the general consensus is that this problem is mainly financial. National funds have decreased due to the international economic crisis.

For the same reason, various medical companies prefer to subsidize their clinical trials at less expensive medical centers than university centers.

Finally, many talented new academic surgeons turn to more profitable choices, that is to the private sector, due to reduced income and merciless, often unethical antagonisms. Thus, day by day, the domain of academic surgery is deprived of new and very promising talented surgeons.

\section{The Researcher}

No academic career is meaningful without active and continuous research.

It is precisely this that distinguishes him in the academic community. The historical course of academic surgery includes brilliant names that have marked the contemporary avenues of surgery.

I shall refer to those academic surgeons who were honored with the ultimate distinction of the Nobel prize and who have left a great heritage of surgery in the international medical knowledge.

Emile Theodore Kocher (1841 - 1917$)$ is the first surgeon to be honored with this highest distinction in 1909 for his pioneering research on the physiology and surgery of the thyroid gland.

Alexis Carel (1883 -1944) received the Nobel prize in 1912 for his experimental research regarding organ transplantation. Frederic Grand Banding, Canadian orthopedic surgeon, honored in 1923 for his pioneering work in discovering insulin. Werner Theodore Otto Forcsman (1924 - 1979) was a German urologist, honored in 1956 for his contribution in heart catheterization.

Charles Brendou Huggins (1901 - 1994) Canadian urologist, honored in1966 for his contribution regarding the hormonic correlation of prostate cancer with testosterone.

In 1990, an American by the name of Joseph Murray, was the last surgeon to be honored for his tremendous experimental contribution to the field of kidney transplantation. Since then, no Nobel prize has been given to a surgeon. I do believe, however, that this will soon change.

Clinical research continues to hold its longstanding honored value and remains a serious concern for the academic surgeon.

The clinical surgeon is authorized to transfer, apply and evaluate (Evidence Based Surgery) the data of basic research in clinical practice.

We must, however, confess that nowadays and for the foreseeable future, basic research has the dominant role and will continue to be the fundamental pillar of the academic edifice. The concern will focus upon the gnostic objects directly related to surgery [4].

I shall mention here, by way of example, the correlation of transplant immunobiology with genetics or tumor immunology with molecules biology. Also, the genetic analysis of risk factors in family colon cancer or, finally, the development of cancer vaccines.

There are some examples where basic research will affect and change our surgical practice. Here again, the surgeon must be an active participant. However, he must also be prepared to experience a new reality, which will emerge after the intervention on the human genome.

Many illnesses will cease to exist such as congenital heart diseases, hereditary illness, malignant neoplasms and others like, for instance, arteriosclerosis. In other words, he must befriend the idea of a new surgical pathology, that is to say, a new surgical reality.

The surgeon will, however, also play a crucial role in clinical research where he must transfer and apply the data of basic research in clinical practice. Not to mention that his participation will be of crucial importance to the establishment in practice of biotechnology achievements like, for example, robotic surgery or imaging technologies.

The indubitable fact remains that the new surgeon is unwilling in our days to participate in research and especially in basic research in the sense of its fulltime and exclusive involvement. There are many reasons for this. Probably, because he lacks the right educational infrastructure and the experience of carrying out basic research. The main reason, however, is the poor financial support which negatively affects both 
his personal as well as his family life.

The academic surgeon - researcher who splits his time is a special case. He is a rider who must keep his balance while riding two horses at the same time. Francis Moore pictures it as a small boat which connects two shores facing each other. It is a tool, which will transfer the knowledge of the biology science to the patient's bed.

However, those staying on the one shore consider him an inadequate scientist where as those residing on the opposite shore sarcastically consider him an incompetent surgeon who dedicates little time to the operating theater. However, his conservation of the tradition of surgical research is of cardinal and crucial importance. These new researches must be mentored for the production of qualitative research, for the production of new knowledge, and to avoid falling into the trap of the lust for numbers (volume) in order to simply enrich a C.V.

I estimate that the academic surgeon must dedicate enough time to research after his qualification without in any way neglecting surgery which establishes him as the surgical personality as I have already pointed out. This is the point at which the leader of the surgical team intervenes. The mentor is he who will enlist new talented researchers, including students, who exhibit the charisma of research and make an ambitious effort to distinguish themselves but also possess the appropriate education and intelligence. These candidates must be guided either to clinical research or to basic research since the leader will secure the right infrastructure but above all, the necessary financial support.

I believe that the personality of the leader plays a decisive role in the creation of staff and new surgeons- researchers and owes it to them to become a point of reference and a model to be imitated. unfortunately, during the last 20 years, State subsidies have invested more in preventative medicine rather than in researches.

This, in my humble opinion, is an erroneous practice which devaluates the quality of the State's presence in this crucial domain.

It is however, an indisputable fact that in the near future research methodology will change as will the use of the means of its application. The use in biomedical research of alternative methods, which may substitute for animal models, is a practice that is constantly gaining ground. These alternative methods have many advantages and low cost. They are not in a position, however, to fully replace the complex biological systems that live models have. For this reason, their value is in question, particularly when reference is made to the level of applied re- search in clinical practice. I personally believe that biological models will continue to offer their invaluable services to research, but within the framework, of the European Union Legislation, such as, for example directive 86/609.

\section{The Teacher}

The Teaching of Surgery is the most fundamental mission and duty of the academic surgeon. Please allow me to focus on the education and training of new surgeons as well as on the education of medical students.

The education and training of new surgeons is more demanding. The education and training of curriculum demands new skills and fresh knowledge, which is the consequence of the explosive innovation of biotechnology.

By way of example, I refer to the application of ultrasound in surgery, laparoscopic and robotic surgery etc. The education and training of new surgeons continues to be based on the learning of surgical practice under the supervision of experienced surgeons.

It is, however, broadly accepted that in the very near future the decisive role in the education and training of surgeons will be played by simulators in conditions of virtual reality.

An interesting point is, however, the rapid evolution of new knowledge as well as the achievements of contemporary biotechnology. It is estimated that half the lifetime of new technologies is 3 to 4 years and constantly decreasing. These conclusions led many new educational and training programs in surgery to prolong the time of post graduate education and training of surgeons.

In my opinion, this is a backward concept because it does not take into consideration: a) the tremendous ability to access knowledge and information in the realms of the internet and b) the new generation is maturing faster.

For these reasons, I am convinced that in the near future the duration of training in various specialties of surgery will shrink considerably.

It is most unfortunate, however, that the education and training of medical students continues to be based on archaic models. Educational programs that persist in a long-term learning process still exist.

Interactive education is totally absent from many universities. Here again, easy access to the source of information is blatantly ignored. I again stress here my firm belief that in the future, the years of medical studies will be reduced. 


\section{The Administrator}

The academic surgeon particularly has to be an administrator in order to keep up with the various obligations imposed by the system.

Some academic surgeons have the innate talent of managing. However, to be able to play the role of leader at local as well as national level it is imperative that he is taught the art of management.

In our country, prior to acquiring the role of leader, the academic surgeon will have gradually experienced various levels of management. Consequently, when he becomes a leader, he is prepared to confront any problems that arise in addition to performing the duties and mission of the teacher as well as those of the surgeon.

Unfortunately, over the last fifteen years the managerial duties of academic surgery have clearly been alienated from the changes that have occurred in the various national health systems. The supply of medical services is regarded as a product, as a commodity and a managerial hegemony is transferred from one person to composite advisory organs or technocrats. The outcome of this managerial metamorphosis in Health care poses a great challenge for the near future. In any event, the end of the managerial hegemony of the academic surgeon is particularly painful and it is indeed accurately described by Patricia Pitcher in her book "The drama of leadership".

\section{The Communicator}

Finally, the best character trait of the academic surgeons, and of equal importance, is his ability to be a good communicator. The simple acquisition of knowledge and skills are not sufficient.

Knowledge must be communicated to the scientific community in a plain and comprehensible way. This demands oral and written skills and abilities, especially in English, which has been established as the primary scientific language. Accomplishing this is a difficult task particularly for non-English speaking scientists.

I very strongly recommend that all surgical trainees participate in courses that provide a good learning experience and enhance effective public speaking.

A dedicated surgical educator must know how to communicate with their audience in variety of settings, such as scientific and surgical meetings, seminars and clinical rounds. His or her role requires the ability to emanate enthusiasm as well as knowledge.

Many believe that writing and public speaking skills come easier to some than to others but for most, they are the result of considerable efforts. The rewards of such efforts are significant and will be harvested at scientific meetings and through published reports in the form of interesting and effective communication with other academic surgeons. This last but not least character trait completes the scientific profile of genuine academic surgeons.

I must now conclude my article. I would say that to choose an academic career is a difficult decision. It is a career that demands hard, non-stop work, that faces tough competition; it is fraught with many letdowns and anxiety and most of all it demands personal as well as family sacrifices [5].

It promises, however, an exciting journey with unbelievable rewards in terms of satisfactions, pleasures and most of all, the justified fulfillment in reaching the peak and realizing the dream: the unique sensation of offering to fellow man.

Personally, I have experienced my academic career the very same way. At this moment in time, were I asked to review my academic lifetime, without the slightest hesitation I would make the same choices and I would gladly start all over again from the very beginning !..

\section{References}

1. William d. Holden: The education of the academic surgeonCanad.Med. Ass. J-. 1966. ; 95.

2. Fabrizio Michelassi: The discovery of new knowledge: Our scientific mission - surgery - $2006 ; 140: 4$.

3. Jonathan Meakins: A career in academic surgery.University of oxford.-www.Medsciox.Ac.Uk/gazette/previousissues/55voll/part 4-

4. J. Bradley: Odyssey of an academic surgeon. Ann surg. 2001 ; 233(5): 597-602

5. Mare R. De leval: From art to science: a fairy tale? The future of academic surgery. Ann Thorac Surg 2001; 72:9-12 